\title{
Pattern of Green Leafhopper Infestation in Boro Rice in Tarai Region of West Bengal Using Distributional and Modular Approach
}

\author{
Pramit Pandit $^{1^{*}}$, K.N. Krishnamurthy ${ }^{1}$, Bishvajit Bakshi ${ }^{1}$, Prithwiraj Dey ${ }^{2}$ and \\ Nripendra Laskar ${ }^{3}$
}

${ }^{1}$ Department of Agricultural Statistics, Applied Mathematics and Computer Science, University of Agricultural Sciences-Bangalore, Karnataka, India

${ }^{2}$ Department of Agronomy, G.B. Pant University of Agriculture \& Technology, India

${ }^{3}$ Department of Agricultural Entomology, Uttar Banga Krishi Viswavidyalaya, India

*Corresponding author

\section{A B S T R A C T}

\section{Keywords \\ Rice-pest modelling, Green leafhopper, \\ Distributional approach, Exponential growth \\ Article Info \\ Accepted: \\ 08 August 2018 \\ Available Online: \\ 10 September 2018}

Recognising the pattern of pest infestation helps greatly to understand the changes in the population dynamics due to several biological, environmental and climatological factors. As data are count in nature, suitable choice of distribution as well as linear or non-linear growth models are obvious to capture the variability present the population. If data are not properly fitted, integrity of scientific inference will be at stake. Hence, in the present study, an attempt has been made to fit appropriate discrete distributions along with the usual linear and non-linear modular approach. Among all the fitted discrete distributions, binomial distribution fits the best, having the minimum Kolmogorov-Smirnov test statistic value and based on different model selection criteria, exponential model is found to be the best fit.

\section{Introduction}

Rice (Oryza sativa L.) is the principal staple food crop of humid, sub-humid as well as semi-arid Asia. In India, rice is grown in different agro-climatic regions on high, medium and low land rice. India has already emerged as the $2^{\text {nd }}$ largest rice producer country of the world.

But from the last two decades, rice yield has become almost stagnant or even declining over time globally (Duxbury et al., 2003). Among the various causes of yield decline, increased pest infestation is of prime importance (Mondal et al., 2017). In recent years, a number of leaf and plant hoppers have assumed serious proportions on the rice crop in various parts of India (Krishnaiah and Varma, 2011).

Though insect count data are discrete in nature, the task of fitting appropriate discrete distributions is generally avoided. By considering only mean values, the loss of informations provided by individual sample observations, is substantial. In the present study, an attempt has been made to fit 
appropriate discrete distributions along with the usual linear and non-linear modular approach.

\section{Materials and Methods}

The current experiment was conducted on the infestation green leafhopper (GLH) on rice at the farm of Uttar Banga Krishi Viswavidyalaya, Pundibari, West Bengal, India $\left(26.52^{\circ} \mathrm{N}, 89.11^{\circ} \mathrm{E}\right)$ during boro season of 2015-16. Size of the field was $15 \times 10 \mathrm{~m}$. The crop was sown in the first week of February and transplanted in the first week of March. No pesticides were used in order to observe natural pest population build up. 15 sample area of size $270 \times 120 \mathrm{~cm}$ were selected using random number table, which covered 32.4 per cent of total experimental area. 13 plants from each sample area were sampled by using ' $W$ ' pattern. Data on Insect counts were recorded from the sampled plants from 21 DAT to 90 DAT (upto harvesting) at 3 days interval.

As the study is empirical in nature, in order to understand the structure of data, different descriptive measures were computed. Geometric distribution has been employed to know when the pest population reaches ETL (Economic Threshold Level) for the first time, considering reaching ETL as success. It also provides an idea about optimum time of spraying pesticides to control green leaf hopper infestation. Binomial distribution has been fitted in order to know on an average how many time points green leaf hopper population remains higher than the ETL. Negative binomial distribution has been fitted (Bliss and Fisher, 1953) to know when the pest population reaches ETL for the second time. Poisson distribution has been fitted with a view to know the average number of insect present in a given day. Probability mass functions of different distributions are presented in table 1.
To relate the times of taking observations and DAT, a conversion formula is so obvious, so that results obtained in time point can be easily converted into DAT and into days for the practical purposes. Mean values of geometric, binomial, negative binomial and poisson distribution have been calculated in terms of time point(s), which further, by the above mentioned formula, have been converted for the purpose of appropriate interpretation.

Time point ' $\mathrm{t}$ ' $=21+(3 * \mathrm{t})$ DAT and

Time point ' $\mathrm{t}$ ' $=(3 * \mathrm{t})$ days.

Kolmogorov-Smirnov test for goodness of fit is used to compare observed sample distribution with some theoretical distribution. It gives idea about how good a theoretical distribution fits to a practical data. Test Statistics is given as:

$\mathrm{D}=\operatorname{Maximum}\left|F_{0}(X)-S_{N}(X)\right|$,

Assuming that samples were drawn from an infinite population, mean of the sample observations has been fitted to various growth models. Linear model assumes a linear relationship between the dependent and independent variable.

It implies that per unit change in independent variable will bring same amount of change in dependent variable. But if the assumption of linear relationship between the dependent and independent variable is not met, when there is presence of one or two humps in the graphical representation of the data, quadratic and cubic model are fitted best, respectively.

When data shows exponential growth or decline, exponential models are employed. For complex type of growth, logistic model is commonly used. Mathematical expression of various linear and nonlinear growth models are presented in table 2 . 
The Akaike information criterion (AIC) is used to provide a means for model selection (Akaike, 1978). It is an estimator of the relative quality of statistical models for a given set of data. Given a collection of models for the data, AIC estimates the quality of each model, relative to each of the other models. AIC is founded on information theory: it offers an estimate of the relative information lost when a given model is used to represent the process that generated the data. In doing so, it deals with the trade-off between the goodness of fit of the model and the simplicity of the model. AIC does not provide a test of a model in the sense of testing a null hypothesis. It tells nothing about the absolute quality of a model, only the quality relative to other models.

AIC $=-2(\log$-likelihood $)+2 \mathrm{~K}$

Similarly, the Bayesian information criterion (BIC) or Schwarz criterion (also SBC, SBIC) is a criterion for model selection among a finite set of models; the model with the lowest BIC is preferred.

It is based, in part, on the likelihood function and it is closely related to the Akaike information criterion (AIC). Lesser the BIC, better the model fits.

$\mathrm{BIC}=\mathrm{k} * \log (\mathrm{n})-2 \log (\mathrm{L}(\overline{\boldsymbol{\theta}}))$

In order to check randomness and normality of residuals of the best fitted model, run test and Kolmogorov-Smirnov test for normality has been employed.

\section{Results and Discussion}

Descriptive Statistics for green leaf hopper count data are computed and presented in table 3. GLH count data has been found to be positively skewed (4.11) and highly leptokurtic (40.43) in nature with mean and variance value 143.67 and 15587.53, respectively. The maximum and minimum number of GLH present in a day per sample during 2015 was 1 and 399, respectively.

From table 4, it can be observed that mean values of geometric, binomial, negative binomial and poison distribution are found to be 63 DAT, 45 days, 66 DAT and 111 insects/sample in a day, respectively (Table 4).

Among all the fitted distributions, binomial distribution showed the minimum Kolmogorov-Smirnov test statistic value presented in table 5, providing the most precise estimate about the experimental data.

Graphical representation of the best-fitted distribution (binomial distribution) is given in figure 1 .

From table 6, it can be seen that in case of GLH count data, among the fitted linear and non-linear growth models, exponential model, graphically represented in figure 2, fitted best with lowest AIC (-19.35) and BIC (-54.39) values, followed by logistic model. Both the coefficients of exponential model (32.852 and 0.101 ) are found to be significant at 1 per cent level.

From table 7 , it can be observed that in a sequence of 24 observations consisting of $12+$ signs $\left(=\mathrm{N}_{1}\right)$ and $12-$ signs $\left(=\mathrm{N}_{2}\right)$, the critical values of runs at the 0.05 level of significance are 7 and 19 as shown in the Tables on run test statistic.

The null hypothesis that residuals are randomly distributed, is nothing to be rejected if the number of runs lies between 7 and 19 . Here as it is found that the number of runs (equal to 12) is greater than 7 and less than 19, we accept (at the 0.05 level of significance) the null hypothesis. Next, we proceed to test for the normality assumptions of the residuals. 
Table.1 Different discrete distributions with their corresponding probability mass function

\begin{tabular}{|c|c|}
\hline Name of the distribution & Mathematical expression \\
\hline Geometric distribution & $\begin{array}{l}\mathrm{P}(\mathrm{X}=\mathrm{x})=q^{x} p, \mathrm{x}=0,1,2, \ldots \\
=0, \text { Otherwise. }\end{array}$ \\
\hline Binomial Distribution & $\begin{array}{l}\mathrm{P}(\mathrm{X}=\mathrm{x})=c_{x}^{n} p^{x} q^{n-x}, \mathrm{x}=0,1, \ldots \mathrm{n} ; \mathrm{q}=1-\mathrm{p} \\
=0, \text { Otherwise. }\end{array}$ \\
\hline Negative Binomial Distribution & $\begin{array}{l}\mathrm{P}(\mathrm{X}=\mathrm{x})=C_{r-1}^{x+1} p^{r} q^{x}, \mathrm{x}=0,1, \ldots ; \mathrm{q}=1-\mathrm{p} \\
=0, \text { Otherwise. }\end{array}$ \\
\hline Poisson Distribution & $\begin{array}{l}P(X=x)=\frac{e^{-\lambda_{\lambda} x}}{x !}, x=0,1,2 \ldots, \lambda>0 \\
=0, \text { Otherwise. }\end{array}$ \\
\hline
\end{tabular}

Table.2 Different linear and nonlinear growth models with their corresponding mathematical expression

\begin{tabular}{|c|}
\hline $\begin{array}{c}\text { Name of the model } \\
\text { Linear }\end{array}$ \\
\hline Quadratic \\
\hline Cubic \\
\hline Exponential \\
\hline Logistic \\
\hline
\end{tabular}

Mathematical expression
$\mathrm{Y}=\mathrm{a}+\mathrm{b} * \mathrm{t}+\varepsilon$
$\mathrm{Y}=\mathrm{a}+\mathrm{b} * \mathrm{t}+\mathrm{c}^{*} \mathrm{t}^{2}+\varepsilon$
$\mathrm{Y}=\mathrm{a}+\mathrm{b}^{*} \mathrm{t}+\mathrm{c}^{*} \mathrm{t}^{2}+\mathrm{d}^{*} \mathrm{t}^{3}+\varepsilon$
$\mathrm{Y}=\mathrm{a}^{*} \mathrm{~b}^{\mathrm{t}}+\varepsilon$
$Y=\frac{1}{1+e^{a+b t}}+\varepsilon$

Table.3 Descriptive Statistics for green leafhopper count data during 2015

\begin{tabular}{|c|c|c|c|c|c|c|}
\hline \multirow{2}{*}{$\begin{array}{c}\text { Name of the } \\
\text { Insect Pest }\end{array}$} & \multicolumn{5}{|c|}{ Descriptive Statistics } \\
\cline { 2 - 7 } & Mean & Variance & Skewness & Kurtosis & Minimum & Maximum \\
\hline GLH & 143.67 & 15587.53 & 4.11 & 40.43 & 1 & 399 \\
\hline
\end{tabular}

Table.4 Parameter estimates and mean values of the fitted distributions for green leaf hopper count data during 2015

\begin{tabular}{|c|c|c|c|c|c|c|c|c|c|c|}
\hline \multirow{3}{*}{$\begin{array}{c}\text { Name } \\
\text { of the } \\
\text { Insect Pest }\end{array}$} & \multicolumn{10}{|c|}{ Parameter estimates and mean values of the fitted distributions } \\
\hline & \multicolumn{2}{|c|}{$\begin{array}{l}\text { Geometric } \\
\text { Distribution }\end{array}$} & \multicolumn{3}{|c|}{$\begin{array}{c}\text { Binomial } \\
\text { Distribution }\end{array}$} & \multicolumn{3}{|c|}{$\begin{array}{l}\text { Negative Binomial } \\
\text { Distribution }\end{array}$} & \multicolumn{2}{|c|}{$\begin{array}{c}\text { Poisson } \\
\text { Distribution }\end{array}$} \\
\hline & $\widehat{\mathbf{p}}$ & Mean & $\mathbf{n}$ & $\widehat{\mathbf{p}}$ & Mean & $\mathbf{r}$ & $\widehat{\mathbf{p}}$ & Mean & $\bar{\lambda}$ & Mean \\
\hline GLH & 0.07 & 14 & 24 & 0.34 & 15 & 2 & 0.12 & 15 & 143.67 & 144 \\
\hline
\end{tabular}


Table.5 Kolmogorov-Smirnov Test Statistic value of the fitted distributions for for green leafhopper count data during 2015

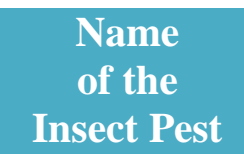

GLH

\section{Kolmogoror
Geometric
Distribution}

$0.5712^{* *}$

leafhopper count data during 2015

** Significant at 1per cent level, NS: Non-significant

\section{Binomial \\ Distribution}

$0.1123^{\mathrm{NS}}$

\section{Negative Binomial}

Distribution
Poisson Distribution

$0.3297^{* *}$

Table.6 Parameter estimates of fitted models for green leaf hopper count data during 2015

\begin{tabular}{|c|c|c|c|c|c|c|}
\hline \multirow{2}{*}{ Model Name } & \multicolumn{4}{|c|}{ Parameter estimates } & AIC & \multirow{2}{*}{ BIC } \\
\cline { 2 - 7 } & a & b & c & d & & \\
\hline Linear Model & $21.061^{\text {NS }}$ & $10.642^{*}$ & - & - & 203.9 & 206.26 \\
\hline Quadratic Model & $-16.621^{\text {NS }}$ & $20.932^{*}$ & $-0.45^{\text {NS }}$ & - & 203.69 & 207.23 \\
\hline Cubic Model & $61.125^{\text {NS }}$ & $-24.553^{\text {NS }}$ & $4.6^{* *}$ & $-0.15^{*}$ & 199.03 & 199.03 \\
\hline Exponential Model & $32.852^{* *}$ & $0.101^{* *}$ & - & - & -19.35 & -16.99 \\
\hline Logistic Model & $0.034^{*}$ & $0.905^{* *}$ & - & - & -15.79 & -12.54 \\
\hline
\end{tabular}

** Significant at 1 per cent level, * Significant at 5 per cent level, NS: Non-significant

Table.7 Runs test for Exponential model for green leaf hopper data during 2015

\begin{tabular}{|c|c|c|c|c|c|c|c|}
\hline Model & $\begin{array}{c}\text { Test } \\
\text { Value }_{\mathrm{a}}\end{array}$ & $\begin{array}{c}\text { Number of } \\
\text { Cases < } \\
\text { Test Value }\end{array}$ & $\begin{array}{c}\text { Number of } \\
\text { Cases }>= \\
\text { Test Value }\end{array}$ & $\begin{array}{c}\text { Total } \\
\text { Number } \\
\text { of Cases }\end{array}$ & $\begin{array}{l}\text { Number } \\
\text { of Runs }\end{array}$ & $\mathbf{Z}$ & $\begin{array}{l}\text { Asymp. } \\
\text { Sig. (2- } \\
\text { tailed }\end{array}$ \\
\hline Exponential & 0.00 & 12 & 12 & 24 & 13 & 0.578 & 0.563 \\
\hline
\end{tabular}

Fig.1 best fitted distribution for green leaf hopper count data during 2015

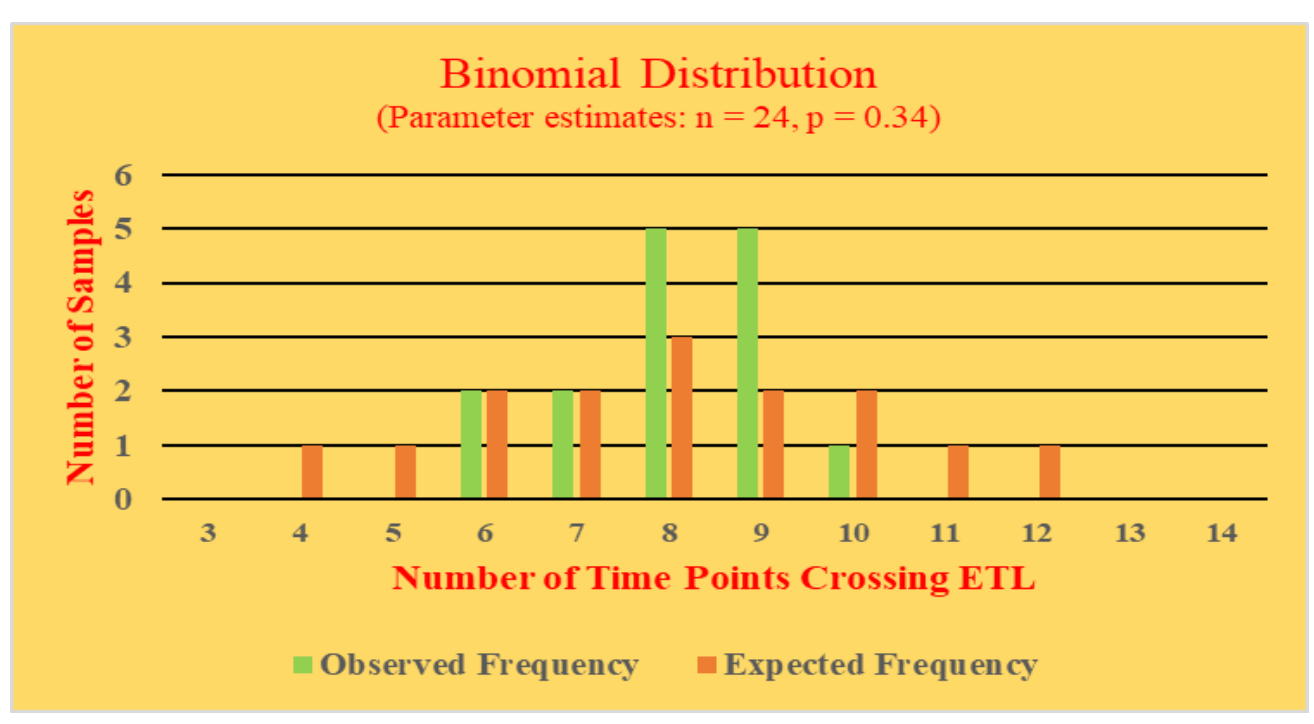


Fig.2 Best fitted model for green leaf hopper count data during 2015

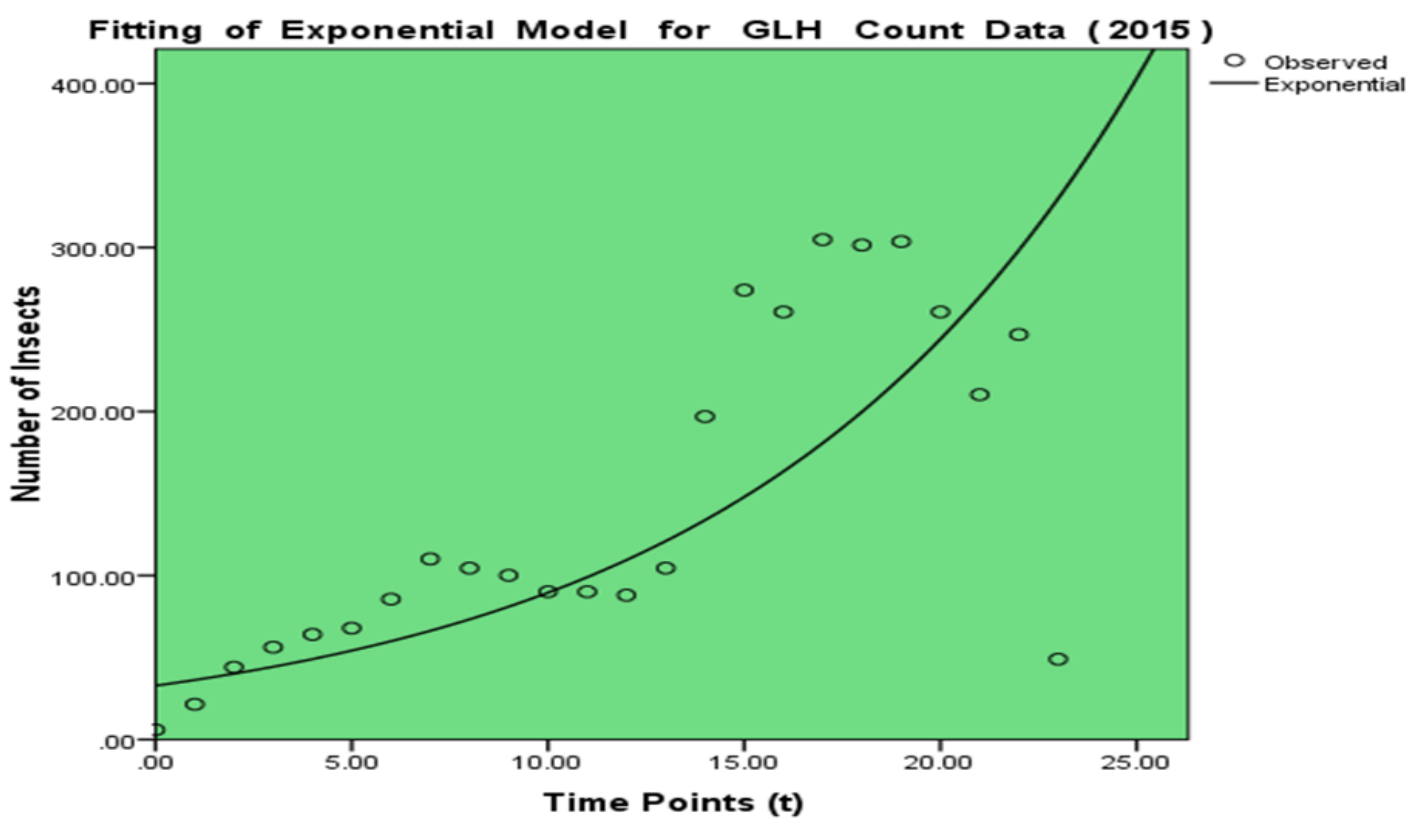

KS Test has been performed and the calculated value of the test statistic is $\operatorname{Dn}(\mathrm{Cal})=$.0.313 and as the calculated value of Dn(Cal.) <Dn(Tab.), $0.05=0.51926$, the null hypothesis (that the observed distribution is normal) is accepted. Thus it is concluded that the residuals are independent and follow normal distribution.

Available literature reveals that large number studies have been conducted regarding various biological aspects of insect pests of rice. Similar kind of studies have also been carried out on modelling of pest population by Das et al., (2017), Basak et al., (2017) and Pal et al.,(2013). Findings of Das et al., (2017) reveal that cubic model to be best fit for rice leaf folder data in Tarai region of West Bengal.

The present study establishes the importance of the usage of discrete distributions and linear as well as non-linear models in order to describe the growth pattern of the green leafhopper population over time. Therefore, the present study considerably helps in formulating forewarning system against green leafhopper infestation in actual field condition.

\section{Acknowledgement}

This research article is a part of Thesis work submitted for M.Sc. (Ag.) in Agricultural Statistics by Mr. Pramit Pandit to UASBangalore in the year 2018. All co-operations received from the co-authors and the financial support provided by ICAR and UASBangalore is duly acknowledged.

\section{References}

Akaike, H. 1978. A Bayesian analysis of the minimum AIC procedure. Ann. Inst. Statist. Math. 30(A):9-14.

Asghar, M., Suhail, A., Afzal, M. and Khan, M.A. 2009. Determination of economics threshold levels for the stem borers (Scirpophaga sp.) and leaf folder (Cnaphalocrosis medinalis) of rice (Oryza sativa) in the Kallar tract of Punjab, Pakistan. International Journal 
of Agriculture and Biology. 11(6):717720.

Basak, S., Das, S. S. and Pal, S. 2017. Nonlinear modelling of rice leaf folder infestation on Boro rice in Pundibari (A part of Cooch Behar district). Journal of Entomology and Zoology Studies. 5(2):967-972.

Bliss, C.A. and Fisher, R.A. 1953. Fitting the Negative Binomial Distribution to Biological Data. Biometrics. 9(2):176200.

Das, S.S., Debnath, M.K., Basak, S., Ghosh, J. and Das, A. 2017. Estimation of optimum time of spray for controlling rice leaf folder infestation on boro rice in terai region of West Bengal using best fitted linear and nonlinear growth model. Int.J.Curr.Microbiol.App.Sci. 6(6): 2300-2309.

Duxbury, J. M., Mayer, A. B., Lauren, J. G. and Hassan, N. 2003. Food chain aspects of arsenic contamination in Bangladesh: effects on quality and productivity of rice. Journal of Environmental Science and Health,
PartA: Toxic/Hazardous Substances and Environmental Engineering. 38(1): 61-69.

Krishnaiah, K. and Varma, N.G. 2011. Changing insect pest scenario in the rice ecosystem-A national perspective. Rice Knowledge Management Portal.pp.1-28.

Mondal, D., Ghosh, A., Roy, D., Kumar, A., Shamurailatpam, D., Bera, S., Ghosh, R., Bandopadhyay, P. and Majumder, A. 2017. Yield loss assessment of rice (Oryza sativa L.) due to different biotic stresses under system of rice intensification (SRI). Journal of Entomology and Zoology Studies. 5(4): 1974-1980.

Shamurailatpam, D., Bera, S., Ghosh, R., Bandopadhyay, P. and Majumder, A. 2017. Yield loss assessment of rice (Oryza sativa L.) due to different biotic stresses under system of rice intensification (SRI). Journal of Entomology and Zoology Studies. 5(4): 1974-1980.

\section{How to cite this article:}

Pramit Pandit, K.N. Krishnamurthy, Bishvajit Bakshi, Prithwiraj Dey and Nripendra Laskar. 2018. Pattern of Green Leafhopper Infestation in Boro Rice in Tarai Region of West Bengal Using Distributional and Modular Approach. Int.J.Curr.Microbiol.App.Sci. 7(09): 1020-1026. doi: https://doi.org/10.20546/ijcmas.2018.709.121 